\title{
An Improvement of Three Leg Signalized Intersections in Duhok City Kurdistan-Iraq
}

\author{
Baran R. Omer ${ }^{1}$, Sherzad W. Khalid ${ }^{2}$ \\ Department of Civil Engineering, College of Engineering, University of Duhok, Zaxo St., Duhok, Kurdistan Region - F.R. Iraq
}

\begin{abstract}
Nowadays, number of cars increases in Iraqi Kurdistan. Duhok is one of the Iraqi Kurdistan cities where an enormous increase in the number of cars and population is noticed during the last decade. Roads were been mended according to the 1970s plans where the city was small and number of cars was few. Although the city geographically is located in a hilly area and between two mountains, mending roads is a problem of area. Roads in the mentioned city are quite busy due to the high number of cars, traffic jams can be noticed in every corner of the city especially in signalized intersections. The level of service (LOS) in most of the signalized intersections is F or E. in order to lower the high (LOS), a three leg signalized intersection has been chosen to do an improvement on. During the study the number of the cars (Volume) have been enumerated in all lane groups and the results showed that the (LOS) was E in the intersection. As a result, some solutions have been provided according to the site area and the traffic flow. Solutions were geometric changes, cycle time changes or combination in both geometric and cycle time changes. According to the collected data, it was found that level of service was E for WB and SB and for EB was D. Based on data analysis it was found that LOS has not been improved when only one of the mentioned solutions is applied. In order to have the best improvement, the combination between geometric and cycle time length changes are applied. Analysis showed that there was a remarkable improvement in LOS and changed from E to D.
\end{abstract}

KEYWORDS : Roads, Intersection, Signalized Intersections, Three leg signalized intersection, Volume, Level of Service, (LOS), Traffic flow, Lane groups, Geometric, Cycle time.

\section{INTRODUCTION}

In every urban, the signalized intersection is important for controlling traffic stream, safety, delay, capacity and level of service (Flaherty, 1997), Highway Capacity Manual HCM (2000) defines Capacity that it is related to congestion in intersections that expressed in term of level of service (LOS) by the highway capacity manual. Capacity is maximum number of vehicles can pass through intersection in a period of time $(1 \mathrm{hr}$.) under specified conditions. The capacity of a signalized intersection increases with signal cycle length so that capacity for short single cycle length is low and by increasing the cycle length it will increase slowly

Academic Journal of Nawroz University

(AJNU) Volume 7, No 4 (2018).

Regular research paper : Published 21 December 2018

Corresponding author's e-mail : baran.omer@uod.ac

Copyright (C2017 Baran R. Omer 1, Sherzad W. Khalid².

This is an open access article distributed under the Creative

Commons Attribution License.
(HCM, 2000) To evaluate designing, safety and operation of signalized intersections, it is important to assess traffic volume. The assessment is to provide enough data to analyze the intersections from the number of cars and geometric dimensions (Slinn and Guest, 2005) Because of the high rate of car-ownership and population growth in the city, capacity of intersections becomes lower than road's capacity. As a result, intersections cannot serve appropriately. This is due to lack of space and unsuitable cycle time length. Therefore, provision of solutions for congestion in the signalized intersections becomes inevitable fact. Regarding to solutions, auxiliary left turn lane and open through lane are usually provided at signalized intersections. In this paper auxiliary left-turn lane, cycle time and open through lane effects were founded at the same time at intersections to evaluate level of service before and after changes. The left-turn lane should be separated from through movement from all other vehicle to enhance the effect. At the same time, signalization can be adopted at which through 
movement for open through always be opened and taking into consideration that there is no pedestrians present. In this case, some overlaps between left turns and other movements are possible which can improve the efficiency of signals and delay time for drivers (Brockenbrough and Boedecker, 2004) Over the last decade, researchers focused on studies on improvements of signalized intersections with cycle time length or opening right and through lanes. In this paper a new idea is presented to improve signalized intersections with the combination between cycle time and geometric changes. These changes include opening left turning lanes on red phase which let the cars to pass on the left through red phase in one of the intersection bound. This will provide passing for $50 \%$ of the stopped cars on red in the same lane group.

\section{Methodology}

\subsection{Signalized intersections}

Signalized intersections are essential in every urban transportation structure. It carries huge amount of vehicles and pedestrians, which, in turn, cause traffic jams in crossing and turnings. Because of availability of many reasons as car ownership, economic and population growth, the carrying capacity of the intersection during peak hours can be exceed the intersection demand. As a result, intersection operation problems and safety risks are concerns. Also, the level of service (LOS) will be low and this will lead to congestion, increase in accidents, increase in fuel consumption, emitted gases and noise. Thus, the city standards of life and energy consumptions deteriorate.

\subsection{Operational measurements}

To evaluate operation of signalized intersections, many measures are effective and generally used. The most effective measurements are; capacity (volume-tocapacity) ratio and delay (Xin and Sulijoadikusumo). The HCM (2000) determines these effective measurements by lane groups. Lane groups include movements at which share the same stop pattern. Exclusive turns (i.e. right turns and open through lanes) are commonly counted as individual lane groups. Lane groups can be specified by approach for the whole intersection (Robinson and Thagesen, 2004).

\subsubsection{Delay}

Delay is defined in HCM (2000) as "the additional travel time experienced by a driver, passenger, or pedestrian". Calculation for control delay and equations are provided in the table 2. The delay is usually derived from the driver experience that is available to the existence of the traffic signal including time spent in queue, decelerating (brake) and accelerating (Thagesen, 1997).

Data has been collected by counting number of cars (volume) per each approach in 5 working days from Sunday to Thursday. Three hours are selected from these days one hour in the morning and two hours afternoon. Then 15 minutes analysis period is used as a typical period (HCM, 2000). Control delay is used as the base for calculating LOS. Intersection control delay is determined as an average of all lane groups based on the traffic volume in each lane group.

Relation between LOS and delay is illustrated by HCM (2000) as in the table 1 below;

Table (1) : LOS Criteria for Signalized Intersection

\begin{tabular}{|c|c|}
\hline LOS & $\begin{array}{c}\text { Control delay per vehicle } \\
\text { (s/veh.) }\end{array}$ \\
\hline A & $10 \leq$ \\
B & $>10-20$ \\
C & $>20-35$ \\
D & $>35-55$ \\
E & $>55-80$ \\
F & $>80$ \\
\hline
\end{tabular}

\subsubsection{Capacity and Capacity to Volume ratio (v/c)}

Capacity is maximum number of vehicles can pass through intersection in a period of time $(1 \mathrm{hr}$.) under specified conditions (Schadschneider et al 2007). Generally, it is estimated according to the assumed values for saturation flow rates. Capacity explained in highways as the lane numbers, lane widths, lane grades and signalization conditions (Chen and Liew, 2003).

\subsection{Level of Service LOS}

Congestion in intersections is expressed in terms of level of service (LOS) by the HCM (2000).

To achieve the LOS, there are some input parameters and as a result LOS will be measured (Federal Highway Administration). The parameters are geometric, traffic and cycle time. Traffic is the number of cars passing through the intersection. Geometric is the dimensions of intersection where as cycle time is the total time at which the intersection serves the traffic. Then from the input parameters lane grouping and demand flow rate with saturation flow rate are measured. Basic equations and calculation are shown in table 2. From lane grouping and demand flow rate peak hour factor PHF is determined. Later, capacity and delays per lane groups are measured (Roess et al, 2004). LOS is determined from the total delay time on the lane group using table 1 .

\section{Results}

Geometric survey and assessments have been conducted at the site to obtain geometric overview and cycle time of the signalized intersection as shown in fig. 1. Also, traffic flow data has been collected and through the data, peak hour volume has been calculated. To calculate LOS, delay time has been found due to some factors and inputs as mentioned previously. All these factors have been calculated in 
table 2. with all necessary equations. These factors are used to determine saturation flow rate. Also, capacity and loss times are calculated in table 3. On the other hand, Lane group capacity, control delay, and LOS determination are calculated in table 4 .

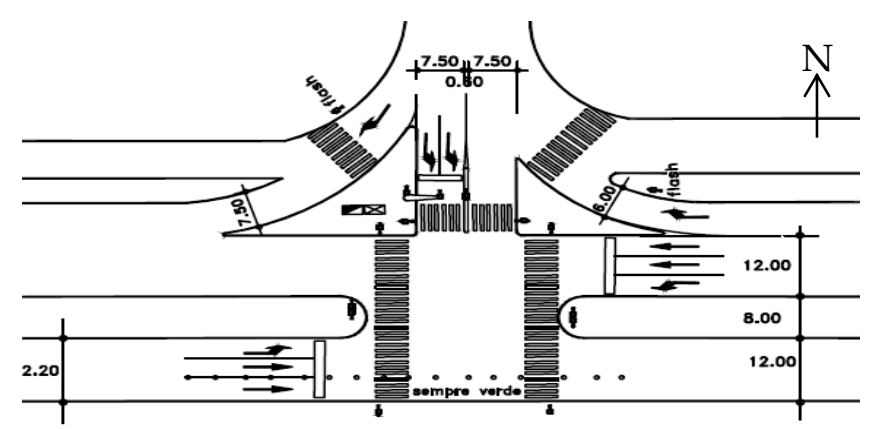

Fig (1) : Intersection plan view

Table (2) : Volume adjustment and saturation flow rate

\begin{tabular}{|c|c|c|c|c|c|c|c|c|c|}
\hline & \multicolumn{3}{|c|}{ WB } & \multicolumn{3}{|c|}{ EB } & \multicolumn{3}{|c|}{ SB } \\
\hline & LT & TH & RT & LT & $\mathrm{TH}$ & RT & LT & $\mathrm{TH}$ & RT \\
\hline Volume & 327 & 2236 & 374 & 772 & 368 & & & 479 & 196 \\
\hline Peak-hour factor,PHF & 0.96 & 0.96 & 0.96 & 0.85 & 0.85 & & & 0.87 & 0.87 \\
\hline $\begin{array}{l}\text { Adjustment flow rate, } \mathrm{Vp}=\mathrm{V} / \mathrm{PHF} \\
\text { (vehicle/hr) }\end{array}$ & 341 & 2329 & 390 & 908 & 433 & & & 551 & 225 \\
\hline \multicolumn{10}{|l|}{ Lane group } \\
\hline Adj. flow rate in lane group & & 3059 & & & 1341 & & & 776 & \\
\hline $\begin{array}{l}\text { Proportion of LT or RT } \\
\text { (PLT or PRT) } \%\end{array}$ & 11.1 & & 12.7 & 67.71 & & & & & 29 \\
\hline \multicolumn{10}{|c|}{ Saturation flow rate } \\
\hline $\begin{array}{l}\text { Base saturation } \\
\text { flow, } S_{\mathrm{o}}(\mathrm{pc} / \mathrm{h} / \ln )\end{array}$ & & 1900 & & & 1900 & & & 1900 & \\
\hline No. of lane, $\mathrm{N}$ & & 3 & & & 3 & & & 2 & \\
\hline Lane width adj. Factor Fw & & 1.05 & & & 1.05 & & & 1.02 & \\
\hline Heavy-vehicle adjustment factor, Fhw & & 0.991 & & & 0.985 & & & 0.992 & \\
\hline Grade adjustment factor Fg & & 0.987 & & & 0.991 & & & 0.983 & \\
\hline Parking adjustment factor, $\mathrm{Fp}$ & 1 & 1 & 1 & 1 & 1 & & & 1 & 1 \\
\hline Bus blockage adjustment factor, Fbb & 1 & 1 & 1 & 1 & 1 & & & 1 & 1 \\
\hline Area type adjustment factor, Fa & 1 & 1 & 1 & 1 & 1 & & & 1 & 1 \\
\hline Lane utilization adjustment factor, Flu & & 1 & & & 1 & & & 1 & \\
\hline Left turn adjustment factor, $\mathrm{Fl}$ & & 0.994 & & & 0.967 & & & 1 & \\
\hline Right turn adjustment factor, Frt & & 1 & & & 0.85 & & & 0.85 & \\
\hline Left turn Ped/bike adjustment factor, flpb & 1 & 1 & 1 & 1 & 1 & & & 1 & 1 \\
\hline $\begin{array}{l}\text { Right turn ped/bike adjustment factor } \\
\text { frpb }\end{array}$ & 1 & 1 & 1 & 1 & 1 & & & 1 & 1 \\
\hline $\begin{array}{c}\text { Adj. saturation flow, } \mathrm{s}(\mathrm{veh} / \mathrm{h}) \\
\mathrm{S}=\mathrm{So} \mathrm{N} \text { fHV fg fp fbb fa flu flt frt flpb frpb } \\
\text { fw }\end{array}$ & & 5834 & & & 4813 & & & 3202 & \\
\hline
\end{tabular}

Therefore, this solution for improvement is not suitable and the other solution which is changing the intersection geometric is suitable for the current situation. Regarding the change in intersection geometry, if we add an auxiliary left turn lane on the median of street 
Table (3) Capacity and loss worksheet

\begin{tabular}{|c|c|c|c|}
\hline & WB & WB & SB \\
\hline Phase number & 1 & 2 & 3 \\
\hline Adjustment Flow Rate, V(veh/h) & 3059 & 1341 & 776 \\
\hline Saturation flow rate, $S($ veh/h) & 5834 & 4813 & 3202 \\
\hline Loss time, $\mathrm{Tl}(\mathrm{s}), \mathrm{tl}=\mathrm{L} 1+\mathrm{Y}-\mathrm{e}$ & 5 & 5 & 5 \\
\hline Effective green time, $(\mathrm{s}) \mathrm{g}=\mathrm{G}+\mathrm{Y}-\mathrm{tl}$ & 29 & 29 & 19 \\
\hline Green ratio, $\mathrm{g} / \mathrm{c}$ & 0.296 & 0.296 & 0.194 \\
\hline Lane group capacity, ${ }^{*} \mathrm{C}=\mathrm{s}(\mathrm{g} / \mathrm{c}),(\mathrm{veh} / \mathrm{h})$ & 1726 & 1424 & 621 \\
\hline $\mathrm{v} / \mathrm{c}$ ratio, $\mathrm{X}$ & 1.77 & 0.94 & 1.25 \\
\hline Flow ratio,v/s & 0.52 & 0.28 & 0.24 \\
\hline Critical lane group/phase(v) & 0.52 & 0.28 & 0.24 \\
\hline $\begin{array}{c}\text { Sum of flow ratios for critical lane groups, } \\
Y_{\mathrm{c}}=\text { sum (critical lane groups, }(\mathrm{v} / \mathrm{c})\end{array}$ & \multicolumn{3}{|c|}{1.05} \\
\hline Total lost time/ cycle,L(s) & \multicolumn{3}{|c|}{0.153} \\
\hline $\begin{array}{c}\text { Critical flow rate to capacity ratio, } \\
X_{\mathrm{C}}=\left(\mathrm{Yc}^{*} \mathrm{C}\right) /(\mathrm{C}-\mathrm{L})\end{array}$ & \multicolumn{3}{|c|}{1.047} \\
\hline
\end{tabular}

Table (4) : Lane group capacity, control delay, and LOS determination

\begin{tabular}{|c|c|c|c|}
\hline & WB & EB & SB \\
\hline \multicolumn{4}{|l|}{ Lane group } \\
\hline Adjusted flow rate, $1 \mathrm{v}(\mathrm{veh} / \mathrm{h})$ & 3059 & 1341 & 776 \\
\hline Lane group capacity $1 \mathrm{c}(\mathrm{veh} / \mathrm{h})$ & 1726 & 1424 & 621 \\
\hline $\mathrm{v} / \mathrm{c}$ ratio, $1 \mathrm{X}=\mathrm{v} / \mathrm{c}$ & 1.77 & 0.94 & 1.25 \\
\hline Total green ratio, $1 \mathrm{~g} / \mathrm{c}$ & 0.296 & 0.296 & 0.194 \\
\hline $\begin{array}{c}\text { Uniform delay, } \mathrm{d} 1=\left(0.5 \mathrm{C}(1-(\mathrm{g} / \mathrm{c}))^{\wedge} 2\right) /(1- \\
[\min (1 . \mathrm{x}) \mathrm{g} / \mathrm{c}])(\mathrm{s} / \mathrm{veh})\end{array}$ & 51 & 34 & 42 \\
\hline Incremental delay calibration, $2 \mathrm{k}$ & 0.5 & 0.5 & 0.5 \\
\hline $\mathrm{D} 2=900 \mathrm{~T}\left[(\mathrm{x}-1)+\operatorname{sqrt}\left[(\mathrm{x}-1)^{\wedge} 2+8 \mathrm{kIX} / \mathrm{CT}\right]\right](\mathrm{s} / \mathrm{veh})$ & 10.8 & 4.4 & 18.1 \\
\hline Uniform delay, d3(s/veh) & 0 & 0 & 0 \\
\hline Progression adjustment factor,PF & 1.286 & 1.063 & 1.051 \\
\hline
\end{tabular}




\begin{tabular}{|c|c|c|c|}
\hline Delay, $\mathrm{d}=\mathrm{d} 1(\mathrm{PF})+\mathrm{d} 2+\mathrm{d} 3(\mathrm{~s} / \mathrm{veh})$ & 77 & 40 & 62 \\
\hline LOS by lane group & $\mathrm{E}$ & $\mathrm{D}$ & $\mathrm{E}$ \\
\hline
\end{tabular}

As shown in calculation tables, the LOS for WB and SB is $\mathrm{E}$ and for EB is D. According to HCM these LOS needs to be improved. To improve, some solutions has been conducted which are; changing green time, geometric changes with opening an auxiliary left turn in one of the bounds or combining both mentioned solutions.

Table (5) : Trials for changing green time in intersection cycle time

\begin{tabular}{|c|c|c|c|c|c|c|c|c|c|}
\hline & \multicolumn{3}{|c|}{ EB } & \multicolumn{3}{c|}{ WB } & \multicolumn{3}{c|}{ SB } \\
\hline Green time (sec.) & 35 & 38 & 40 & 25 & 24 & 25 & 20 & 18 & 15 \\
\hline LOS by lane group & E & D & D & D & E & D & D & D & F \\
\hline
\end{tabular}

Therefore, this solution for improvement is not suitable and the other solution which is changing the intersection geometric is suitable for the current situation.

Regarding the change in intersection geometry, if we add an auxiliary left turn lane on the median of street

with $3.75 \mathrm{~m}$ wide on the East bound (see fig. 2 and 3) and leave the cycle time of the intersection as exists. It will provide an extra lane in the lane group. This lane will stay on green during the green on the north bound which is $50 \%$ of the left turn vehicles in East bound lane group will turn left when the South bound traffic signal is on green time. According to the calculations on volume and delay time, this will show that there is an improvement only on west bound lane group. Also, this solution is not suitable as there will not be improvement in whole intersection.

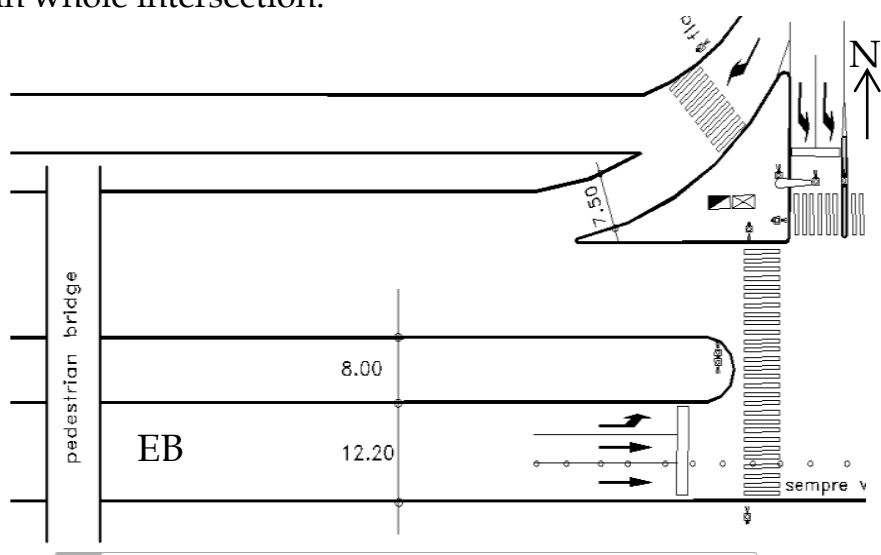

Fig (2) : East bound before adding auxiliary left turn lane
Firstly, changing green time inside the intersection cycle time for all bounds have been performed and some trial and error has been conducted to obtain the best LOS. The results show that, if there is an improvement in two bounds the other will remain the same or worst. As shown in the table 5 below.

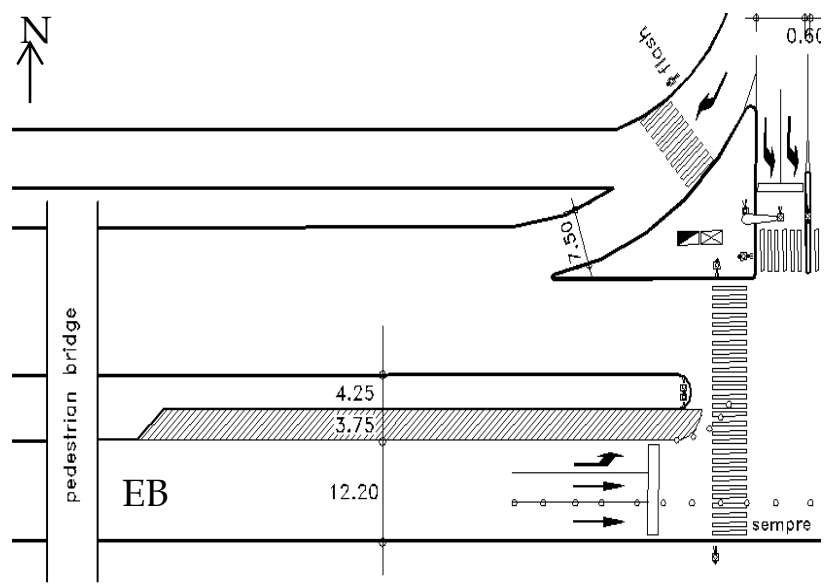

Fig (3) : East bound after adding auxiliary left turn lane To improve whole intersection lane groups, both solutions are combined. Same input parameters in tables 1, 2 and 3 are used to recalculate all requirements for determining LOS. An auxiliary left turn lane is opened with $3.75 \mathrm{~m}$ with taking into consideration that the pedestrian in the East bound has to be eliminated. This lane will operate during the green time on South bound and pedestrian will use the pedestrian bridge where is $80 \mathrm{~m}$ far away from the traffic signal in the East bound as shown in figure 2 . The auxiliary left turn lane will provide more space for cars which will lead to decrease the $\mathrm{v} / \mathrm{c}$ ration in the lane group and control delay time. Also, green time has changed with some trial and errors to get a better LOS than the existing LOS. As a result, there was a remarkable improvement on all lane groups which is D as shown in the tables 6 . This LOS is acceptable according to AASHTO (2004). 
TABLE (6) : Results for combination of both solutions of changing geometric and green time in intersection cycle

\begin{tabular}{|c|c|c|c|}
\hline \multicolumn{4}{|c|}{ time } \\
\hline & WB & EB & SB \\
\hline $\begin{array}{l}\text { Green time } \\
\text { (sec.) }\end{array}$ & 40 & 20 & 20 \\
\hline $\begin{array}{l}\text { Delay } \\
\text { (s/veh) }\end{array}$ & 52 & 53 & 44 \\
\hline $\begin{array}{l}\text { LOS by lane } \\
\text { group }\end{array}$ & $\mathrm{D}$ & $\mathrm{D}$ & $\mathrm{D}$ \\
\hline
\end{tabular}

\section{Conclusion}

The study is referring to improvement in three leg intersections in Duhok city, KR-Iraq. The result of the study is the function of the LOS which is calculated by its relationship to the control delay time (HCM, 2000). The result of the study shows that the LOS in the studied three leg intersection is E which is unfavorable and unacceptable LOS according to AASHTO (2004). This low LOS is influenced by the $\mathrm{v} / \mathrm{c}$ ratio. Whenever the $\mathrm{v} / \mathrm{c}$ ratio is high the LOS will be low and via verse.

As the LOS is unfavorable, the intersection needs an improvement. To improve, some solutions are suggested. These solutions were geometric and green time changes. Firstly, when changing only the green time in all bounds, the results from calculations showed that there was no improvement to be noticed. Therefore, this was not the required solution. On the other hand, when changing in geometric of the intersection which is only from East bound due to the availability of space area in the intersection, the result showed that there is no improvement in the intersection situation. Therefore, It has been shown from analysis that when one of the solutions to be used individually, no improvement will be found. Thus, both solutions were combined and suggested together. Analysis from the combination of both solutions gave a better LOS in the whole intersection. This improvement is for the current situations. But if the population and economic growth is considered for the next decade the LOS will be much worse than nowadays. However the current improvement is acceptable but to improve it to the best, it is suggested to construct interchange.

\section{Acknowledgment}

The authors are thankful to fourth year student (Hisham, Nazdar, Sherihan and Zang) in University of Duhok- College of Engineering for providing data from the intersection.

\section{References}

1. American Association of State Highway and Transportation Officials (AASHTO), A Policy on Geometric Design of Highways and Streets, Fifth Edition, 753-755,(2004).

2. Schadschneider, T.Poschel, R. Kuhme, M.
Schreckenberg, D.E. Wolf. "Traffic and Granular Flow", Springer-Verlag Berlin Heideberg, (2007).

3. Bent Thagesen, "Highway and Traffic Engineering in Developing Countries", by E \& FN Spon , London (1997).

4. Federal Highway Administration, US Department of Transportation. Retrieved from https:// safety.fhwa.dot.

gov/intersection/conventional/signalized/fhwasa1302 7/ch7.cfm

5. Highway Capacity Manual (HCM) (2000). Transportation

6. Research Board, National Research Council,Washington D.C., (2000).

7. M. Slinn, P. Matthewes, P.Guest, "Traffic Engineering Design, Principles and Practice", 2nd Edition, Elsevier Ltd, (2005).

8. O'Flaherty, C.A., “Transportation Planning and Traffic Engineering", (1997).

9. Roess, R.P. and Prassas, E.S. and Mcshane, W.R., "Traffic Engineering",Pearson Prentice Hall, 3rd Edition,( 2004).

10. R.L. Brockenbrough, K.J. Boedecker,JR., "Highway Engineering Handbook", 2nd Edition,McGraw Hill, (2004).

11. R. Robinson, B. Thagesen, "Road Engineering for Development", 2nd Edition,Spon press,London (2004).

12. W.F. Chen, and J.Y. Richard Liew "The Civil Engineering Handbook", 2nd Edition,CRC press LLC, (2003).

13. Xin Yu and Goro Sulijoadikusumo. Assessment of Signalized Intersection Capacity in Response to Downstream Queue Spillback. Retrieved from https://www.westernite.

org/annualmeetings/12_Santa_Barbara/Compendium /2C-Yu-Sulijoadikusumo.pdf. 